\title{
A BNCC e os impactos no currículo do Ensino
} Médio Integrado

The BNCC and the impacts on the curriculum on the Integrated High School

Viviane Aquino Zitzke ${ }^{1}$, Elisane Ortiz de Tunes Pinto ${ }^{2}$

\begin{abstract}
RESUMO
Este ensaio sobre a Base Nacional Comum Curricular (BNCC), recentemente lançada pelo Ministério da Educação (MEC), busca realizar interlocuções com os textos que discutem a Educação Profissional Técnica e o Ensino Médio Integrado, analisando os impactos do documento no Ensino Médio Integrado à Educação Profissional Técnica, desenvolvida nos Institutos Federais de Educação, Ciência e Tecnologia (IFs). Procura, também, refletir sobre o futuro do Ensino Médio Integrado e o seu lugar nas políticas públicas a partir da BNCC e os itinerários formativos.
\end{abstract}

Palavras-chave: BNCC; ensino médio integrado à educação profissional técnica; itinerários formativos.

\section{ABSTRACT}

This essay on the National Curricular Joint Base (BNCC), recently launched by the Ministry of Education (MEC), seeks to carry out dialogues with the texts that discuss Technical Vocational Education and Integrated Secondary Education, analyzing the impacts of the document on Integrated High School Professional Technical Education, developed in the Federal Institutes of Education, Science and Technology (IFs). It also seeks to reflect on the future of Integrated Higher Education and its place in public policies from the BNCC and the training itineraries.

Keywords: BNCC; integrated secondary education to technical vocational education; formative itineraries.

\section{INTRODUÇÃO}

A educação para o ofício ou para o trabalho traz a sua origem do Brasil Colônia quando, "ainda no interior das comunidades nativas, saberes eram passados dos mais velhos aos mais novos através, de práticas relacionadas à caça, pesca, plantio, colheita e construção de objetos." (PASSOS, 2018, p.16). Em 1809, com a criação do Colégio de Fábricas, a educação passa a ser formalmente institucionalizada,

\footnotetext{
${ }^{1}$ Instituto Federal de Educação, Ciência e Tecnologia Sul-rio-grandense - IFSul, câmpus Pelotas - Visconde da Graça (CaVG), Pelotas/RS - Brasil. E-mail: viviane.zitzke@gmail.com

${ }^{2}$ Idem. E-mail: elisane.ortiz@gmail.com
} 
acontecimento considerado como o marco da Educação Profissional no Brasil. Somente em 1909, com a justificativa de prover os "desfavorecidos da fortuna", é promulgado o decreto de criação das Escolas de Aprendizes Artífices, dando início à Educação Profissional no país. Desde então, a educação profissional ocupou um lugar subalterno, sendo tratada marginalmente no sistema educacional brasileiro.

Com a aprovação da Lei de Diretrizes e Bases da Educação Brasileira (LDB), em 1996, a educação brasileira passou a ser dividida em educação básica e educação superior, sendo o ensino médio entendido como etapa final da educação básica, e outras duas modalidades abrangendo a educação especial e a educação de jovens e adultos, excluindo a Educação Profissional dessa divisão, destinando um capítulo apartado na LDB, portando, desconsiderando-a como um nível educacional, mas sim como uma modalidade complementar da educação básica. (ROBALLO; LOTTERMANN, 2016).

Essa dualidade histórica foi reforçada com a edição do Decreto 2.208/1997, que regulamentava a Educação Profissional da LDB, determinando a separação do ensino técnico do ensino médio, causando mazelas que se refletem até os dias atuais. Com a sua revogação pelo Decreto № 5.154/2004, a possibilidade da integração entre o ensino médio e a educação profissional foi restaurada, além de manter as formas subsequente e concomitante prevista no decreto anterior.

A Educação Profissional ganhou evidência com a criação da Rede Federal de Educação Profissional, Científica e Tecnológica e dos Institutos Federais de Educação, Ciência e Tecnologia, através da Lei no 11.892/2008, expandindo a Educação Profissional por todo território nacional. Os Institutos Federais de Educação, Ciência e Tecnologia, se estruturaram a partir de instituições de ensino existentes e atuantes, como os CEFETs, escolas técnicas e agrotécnicas federais, entre outras. Diferentemente das Universidades, os Institutos participam da formação dos indivíduos desde a educação básica, ofertando ao estudante a continuação dos estudos nos níveis seguintes, ou seja, no ensino superior e pós-graduação, promovendo também a pesquisa e extensão. (ZITZKE, 2018).

Respeitando a trajetória da Educação Profissional no país, este artigo traz para si a tarefa de analisar o texto da Base Nacional Comum Curricular (BNCC), em diálogo com texto e autores que discutem os possíveis impactos para o Ensino Médio Integrado e a sua manutenção na educação brasileira.

\section{BNCC E A EDUCAÇÃO PROFISSIONAL TÉCNICA DE NÍVEL MÉDIO OU ENSINO MÉDIO INTEGRADO À EDUCAÇÃO PROFISSIONAL TÉCNICA}

Neste artigo serão levantadas algumas considerações acerca dos efeitos da BNCC na organização curricular, mais especificamente, no Ensino Médio Integrado à Educação Profissional Técnica (EMIEPT) ${ }^{3}$ ou Educação Profissional Técnica de Nível Médio.

O reconhecimento da Educação Profissional na Lei de Diretrizes e Bases da Educação Nacional (LDB) foi "construída a partir de intensa participação do governo e da sociedade civil em discussões travadas desde a década de 1970, [...]" sendo,

\footnotetext{
${ }^{3}$ Será empregado o termo EMIEPT (Ensino Médio Integrado à Educação Profissional Técnica) para designar a Educação Profissional Técnica de Nível Médio na forma Articulada e Integrada ao Ensino Médio.
} 
portanto, a LDB "um importante instrumento de estudo para o entendimento das diferentes concepções da EP no Brasil nas últimas décadas." (AFONSO; GONZALEZ, 2016, p.720).

A Educação Profissional Técnica (EPT), além da LDB (Art. 36-A), encontra amparo legal na Resolução CNE/CEB no 6/2012, que define as Diretrizes Curriculares Nacionais para a Educação Profissional Técnica de Nível Médio (DCNEPTNM), determinando que a Educação Profissional Técnica de Nível Médio seja “desenvolvida nas formas articulada e subsequente ao Ensino Médio, podendo a primeira ser integrada ou concomitante a essa etapa da Educação Básica".

O enfoque das discussões neste ensaio teórico trata da modalidade de Educação Profissional Técnica de Nível Médio na forma Articulada e Integrada ao Ensino Médio ou denominada por Ensino Médio Integrado à Educação Profissional Técnica (EMIEPT).

A organização curricular do EMIEPT se diferencia do ensino médio tradicional por apresentar um currículo que busca relacionar os conhecimentos da formação geral com os da formação técnica, proporcionando a integração dos conteúdos, promovendo a unificação dos conhecimentos e conferindo sentido de continuidade do aprendizado. (RAMOS, 2011; FRIGOTTO; CIAVATTA; RAMOS, 2012; ZITZKE, 2018).

Corroborando nesta direção, Santos $(2017$, p.2) afirma que “é o currículo que define o que deve ser ensinado, é o currículo que orienta o trabalho docente, enfim, o currículo é um dos elementos que se relacionam mais diretamente com as experiências dos estudantes na sua trajetória escolar".

Buscando contextualizar o currículo escolar na BNCC, verifica-se que a reforma do Ensino Médio teve sua origem na Lei no 13.415/2017, decorrente da Medida Provisória no 746/2016, que alterou a Lei de Diretrizes e Bases da Educação (LDB), culminando com a edição da Base Nacional Comum Curricular (BNCC), apresentada como um documento normativo que define as "aprendizagens essenciais que todos os alunos devem desenvolver ao longo das etapas e modalidades da Educação Básica [...]" (BRASIL. BNCC, 2018, p.7, grifo do autor).

Neste sentido, currículo, sendo o documento que "determina o que deve ser ensinado" (SANTOS, 2017, p.2), com a reforma do ensino médio, passa a ser composto pela BNCC e por itinerários formativos ${ }^{4}$, ofertados através de diferentes arranjos curriculares, sendo eles:

$$
\begin{aligned}
& \text { I - linguagens e suas tecnologias; } \\
& \text { II - matemática e suas tecnologias; } \\
& \text { III - ciências da natureza e suas tecnologias; } \\
& \text { IV - ciências humanas e sociais aplicadas; e, }
\end{aligned}
$$

\footnotetext{
${ }^{4}$ Termo definido pelas Diretrizes Curriculares Nacionais do Ensino Médio, Resolução no 3/2018 do CNE/CEB Art. 6a , inciso III, “itinerários formativos: cada conjunto de unidades curriculares ofertadas pelas instituições e redes de ensino que possibilitam ao estudante aprofundar seus conhecimentos e se preparar para o prosseguimento de estudos ou para o mundo do trabalho de forma a contribuir para a construção de soluções de problemas específicos da sociedade". Disponível em: < http://portal.mec. gov.br/docman/novembro-2018-pdf/102481-rceb003-18/file>. Acesso em: 24 jan. 2019.
} 
V - formação técnica profissional (LDB, Art. 36; ênfases adicionadas). (BRASIL. BNCC, 2018, p.468, grifo nosso).

O Conselho Nacional de Educação (CNE) e a Câmara de Educação Básica (CEB), paralelamente a reforma do ensino médio, trabalharam na atualização das Diretrizes Curriculares Nacionais para o Ensino Médio (DCNEM), detalhando a aplicação da BNCC nas escolas. Então, para as DCNEM, currículo é denominado conforme abaixo:

Art. 70 O currículo é conceituado como a proposta de ação educativa constituída pela seleção de conhecimentos construídos pela sociedade, expressando-se por práticas escolares que se desdobram em torno de conhecimentos relevantes e pertinentes, permeadas pelas relações sociais, articulando vivências e saberes dos estudantes e contribuindo para o desenvolvimento de suas identidades e condições cognitivas e socioemocionais. (BRASIL. DCNEM, 2018, p.4).

Assim posto, o novo modelo de ensino médio estabelecido pelas legislações, decompõem as disciplinas em cinco áreas do conhecimento sendo, linguagens, matemática, ciências da natureza, ciências humanas e sociais aplicadas e formação técnica e profissional, propondo a flexibilização curricular a critério do estudante.

O texto apresenta apenas duas disciplinas obrigatórias ao longo dos três anos (Língua Portuguesa e Matemática), deixando as demais disciplinas propostas em áreas de conhecimento. De acordo com Silva $(2019$, p.1) “Essa determinação reduz o currículo do Ensino Médio, bem como a formação dos estudantes, a uma dimensão limitada ancorada exclusivamente em critérios de desempenho postos pelas avaliações em larga escala."

Para a BNCC uma das finalidades do ensino médio é atender às expectativas dos estudantes e às demandas da sociedade, fazendo com que a escola

[...] garanta aos estudantes ser protagonistas de seu próprio processo de escolarização, reconhecendo-os como interlocutores legítimos sobre currículo, ensino e aprendizagem. Significa, nesse sentido, assegurarIhes uma formação que, em sintonia com seus percursos e histórias, permita-lhes definir seu projeto de vida, tanto no que diz respeito ao estudo e ao trabalho como também no que concerne às escolhas de estilos de vida saudáveis, sustentáveis e éticos. (BRASIL. BNCC, 2018, p.463) (grifo do autor).

Neste sentido, a BNCC subtrai áreas importantes para a formação integral do estudante, delegando a este a responsabilidade da livre escolha das demais disciplinas ou áreas do conhecimento do seu interesse, fundamentais para a construção do seu "projeto de vida", anunciando um "protagonismo juvenil" prematuro.

A BNCC chega como um documento salvador da educação, prometendo equidade social e pedagógica onde "todos os problemas relativos à educação são percebidos como problema de falta de conhecimento por parte dos alunos, dos professores, da sociedade [...]", nesse caso "o conhecimento torna-se também um objeto a ser mensurado e avaliado, tomado como indicador da 'boa' qualidade da educação." (CUNHA; LOPES, 2017, p.28,30). 
No que diz respeito à Educação Profissional Técnica (EPT), apresentada no quinto itinerário formativo, esta se diferencia dos demais percursos, que se vinculam a uma determinada área do conhecimento. Apesar de se mostrar articulada ao ensino médio, se distancia da formação integrada na medida em que se apresenta como um itinerário formativo, aparte da formação geral do ensino médio (FERRETTI, 2018), reforçando a separação da formação geral, ou seja, reafirmando a dualidade estrutural historicamente atribuída à Educação Profissional. (CUNHA, 2000a, 2000b, 2000c; CIAVATTA; RAMOS, 2011; ZITZKE et al., 2017).

As DCNEM/2018 determinam que os sistemas de ensino devam ofertar mais de um itinerário formativo por município e em áreas distintas, garantindo aos estudantes a escolha de diferentes arranjos curriculares (BRASIL. DCNEM, 2018, art. 12, § 60, p.8), limitando a oferta de um ensino médio com formação ampla e diversificada, como o atual. A legislação permite o livre acesso das redes privadas ${ }^{5}$, na forma de parceria, na oferta do itinerário de formação técnica e profissional, favorecendo ao desmantelamento e precarização dos docentes da área técnica. (BRASIL. DCNEM, 2018, art. 15, § 6ㅇ, p.9).

Ainda são muito recentes as mudanças na estrutura do ensino médio, sobretudo na Educação Profissional Técnica, e os impactos desta reconfiguração ainda se encontram na fase de expectativa da implantação da BNCC nos Institutos Federais.

Ao longo da história da Educação Profissional no Brasil observamos o caminho trilhado pelas escolas técnicas até chegar aos Institutos Federais.

Os centros federais de educação tecnológica (Cefets), as escolas agrotécnicas federais e as escolas técnicas vinculadas às universidades que aceitaram o desafio desaparecem enquanto tais, para se transformarem nos campi espalhados por todo o país, fiadores de um ensino público, gratuito, democrático e de excelência. Com os Institutos Federais iniciamos uma nova fase, abandonando o hábito de reproduzir modelos externos e ousando inovar a partir de nossas próprias características, experiências e necessidades. (PACHECO, 2011, p.15).

Assim sendo, conta como missão, principalmente, a formação integral considerando o trabalho como princípio educativo, dando ênfase ao EMIEPT que cumpre um papel de educação humanística e integral, considerando a educação para a cidadania e para o mundo do trabalho, como complementares, unidas em um só currículo. Porém, o caminho percorrido, e que começou a germinar a partir do Decreto № 5.154/2004, corre riscos de ruptura antes mesmo de chegarmos ao ideal do ensino técnico integrado.

No art. 4으, parágrafo 1 , inciso I do decreto, temos:

A articulação entre a educação profissional técnica de nível médio e o ensino médio dar-se-á de forma:

\footnotetext{
${ }^{5}$ Entendendo aqui o fortalecimento e a inserção da iniciativa privada na educação pública, como o Sistema "S" (formado pelo SENAI, SENAC, SESI, SESC, SENAR), que se apresenta como um sistema paralelo ao ensino formal de educação profissional, ofertado pelos Institutos Federais de Educação, Ciência e Tecnologia (IFs), oferecendo cursos de formação mais rápida para atender ao mercado conforme discussões em Cunha (2000c) e Manfredi (2016).
} 
I - integrada, oferecida somente a quem já tenha concluído o ensino fundamental, sendo o curso planejado de modo a conduzir o aluno à habilitação profissional técnica de nível médio, na mesma instituição de ensino, contando com matrícula única para cada aluno. (BRASIL, 2004).

É importante refletirmos que tal articulação de forma integrada vai além da simples matrícula única. É uma proposta de formação que atua na qualificação técnica, no ensino de uma profissão, aliada a formação geral que considera o estudante como um ser único, desfazendo a antiga dicotomia entre o intelectual e o braçal.

Conforme nos aponta Pacheco (2011, p.11):

Nosso objetivo central não é formar um profissional para o mercado, mas sim um cidadão para o mundo do trabalho - um cidadão que tanto poderia ser um técnico quanto um filósofo, um escritor ou tudo isso. Significa superar o preconceito de classe de que um trabalhador não pode ser um intelectual, um artista. A música, tão cultivada em muitas de nossas escolas, deve ser incentivada e fazer parte da formação de nossos alunos, assim como as artes plásticas, o teatro e a literatura. Novas formas de inserção no mundo do trabalho e novas formas de organização produtiva como a economia solidária e o cooperativismo devem ser objeto de estudo na Rede Federal.

A BNCC e os itinerários formativos nos trazem à tona a antiga dualidade estrutural na educação, ou seja, a distinção que há muito se discute no ensino profissional, pois considera a formação dissociada do intelectual e profissionalizante, ou seja, nos permite questionar se a Educação Profissional continuará oferecendo um futuro reservado aos filhos da classe trabalhadora oportunizando aos mesmos o acesso à universidade e não retroceder como mera educação compensatória.

Ainda segundo Pacheco (2011, p.12), os Institutos Federais têm em seu mote a discussão de um projeto pedagógico capaz de transformar os sujeitos, construindo "novos sujeitos históricos, aptos a se inserir no mundo do trabalho, compreendendo-o e transformando-o na direção de um novo mundo possível [...]."

Frente às reflexões que a história da criação dos Institutos Federais nos permite, nos vemos em um caminho obscuro, sem saber os rumos e os impactos que a BNCC pode trazer ao ensino profissional, sobretudo ao ensino médio integrado. Restam-nos indagações tais como: que currículo ${ }^{6}$ teremos? Diante das possibilidades que estão nos sendo impostas, podemos vislumbrar um futuro para o Ensino Médio Integrado dos Institutos Federais? Quais impactos na proposta de verticalização do ensino técnico e tecnológico?

\section{CONSIDERAÇÕES FINAIS}

Tanto as DCNEM como a BNCC, publicados em novembro e dezembro de 2018, respectivamente, chegam à sociedade como documentos acéfalos, cujas gêneses não partem da discussão ampliada com a comunidade científica, com as escolas e estudante e com a sociedade civil, acarretando entendimentos controversos. Entre

\footnotetext{
${ }^{6}$ Cabe ressaltar que o campo do currículo se apresenta muito mais abrangente das aproximações realizadas neste ensaio e, portanto, não se esgotam, merecendo discussões mais aprofundadas.
} 
estudiosos da área do currículo, apesar de posições divergentes, também existe uma rejeição à BNCC. (SANTOS 2017).

A ANPED (Associação Nacional de Pós-graduação e Pesquisa em Educação), através do Grupo de Trabalho sobre Currículo (GT 12), se manifestou contrariamente a estrutura que os estudos da BNCC estavam seguindo, ou seja, reforçando a "hegemonia de uma única forma de ver os estudantes, seus conhecimentos e aprendizagens, bem como as escolas, o trabalho dos professores, os currículos e as avaliações, imprópria a escola publica universal, gratuita, laica e de qualidade para todos." (ANPED, 2015). Esforços estes desprezados pelos órgãos competentes e reiterados no texto legal publicado em 2018.

Uma legislação que nasce desconsiderando os diversos estudos realizados ao longo de décadas, que não parte das vivências escolares, que desprestigia as diversidades de cada escola, se apresenta como um instrumento limitado, engessado, "no momento mesmo de suas proposições, visto que os educadores reinterpretam os dispositivos normativos e atribuem a eles novos significados" (SILVA, 2018, p.13), se distanciando da sua finalidade, quer seja, de padronizar e de unificar o ensino médio.

Outro ponto a ser analisado se debruça na esperança de que a BNCC solucionará a baixa qualidade da educação apostando na "promessa de que os educandos serão sujeitos criativos, autônomos, participativos, cooperativos não é somente ilusório como é perverso" (CUNHA; LOPES, 2017, p.31), mas também ingênuo em acreditar que um currículo único conferirá equidade de ensino e aprendizagem, dada a diversidade posta em todo território nacional.

Neste sentido, a BNCC subtrai áreas importantes para a formação integral do estudante delegando a este a responsabilidade da livre escolha das demais disciplinas ou áreas do conhecimento do seu interesse, fundamentais para a construção do seu 'projeto de vida', anunciando um 'protagonismo juvenil' prematuro. Portanto, atribuir a responsabilidade ao estudante de desenhar seu percurso formativo, no mínimo é oferecer um caminho mais curto para a sua formação, acarretando prejuízos futuros que, para muitos jovens, será impossível de reparar devido a sua necessidade de trabalhar ou de auxiliar a família.

Quanto a Educação Profissional Técnica, foco do estudo, permanece no aguardo das discussões e os possíveis desdobramentos da implantação da BNCC pelos Institutos Federais.

Espera-se que os movimentos de repúdio à BNCC sejam ouvidos e que, as legislações que aviltam os direitos da aprendizagem livre, cedam a um processo respeitoso e democrático.

\section{REFERÊNCIAS}

AFONSO, A. M.; GONZALEZ, W. C. Educação Profissional e Tecnológica: análises e perspectivas da LDB/1996 à CONAE 2014. Ensaio: Avaliação e Políticas Públicas em Educação, Rio de Janeiro, v.24, n.92, p.719-742, jul./set. 2016. 
ANPED. Ofício № 1 de 2015. Exposição de motivos sobre a Base Nacional Comum Curricular. Rio de Janeiro: 2015. Disponível em: < http://www.anped.org.br/ sites/default/files/resources/Of_cio_01_2015_CNE_BNCC.pdf>. Acesso em: 24 jan. 2019.

BRASIL. Lei № 9.394, de 20 de dezembro de 1996. Alterada pela Lei № 11.741, de 16 de julho de 2008 e Lei № 13.415, de 16 de fevereiro de 2017. Disponível em: <http://www.planalto.gov.br/ccivil_03/-Leis/19394.htm> e <http://www. planalto.gov.br/ccivil_03/Ato2015-2018/2017/Lei/L13415.htm\#art4>, respectivamente. Acesso em: 22 jan. 2019.

BRASIL. Lei № 11.741, de 16 de julho de 2008. Altera dispositivos da Lei № 9.394, de 20 de dezembro de 1996, que estabelece as diretrizes e bases da educação nacional, para redimensionar, institucionalizar e integrar as ações da educação profissional técnica de nível médio, da educação de jovens e adultos e da educação profissional e tecnológica. Disponível em: < http://www. planalto.gov.br/ccivil 03/Ato2007-2010/2008/Lei/L11741.htm\#art2 >. Acesso em: 21 jan. 2019.

BRASIL. Lei № 11.892 de 29 de dezembro de 2008. Institui a Rede Federal de Educação Profissional, Científica e Tecnológica, cria os Institutos Federais de Educação, Ciência e Tecnologia, e dá outras providências. Brasília, 2008. Disponível em: <http://www.planalto.gov.br/ccivil_03/_ato2007-2010/2008/lei/ I11892.htm>. Acesso em: 20 jan. 2019.

BRASIL. Lei № 13.415, de 16 de fevereiro de 2017. Altera as Leis nos 9.394, de 20 de dezembro de 1996, que estabelece as diretrizes e bases da educação nacional, e 11.494, de 20 de junho 2007, que regulamenta o Fundo de Manutenção e Desenvolvimento da Educação Básica e de Valorização dos Profissionais da Educação, a Consolidação das Leis do Trabalho - CLT, aprovada pelo Decreto-Lei № 5.452, de 1 de maio de 1943, e o Decreto-Lei № 236, de 28 de fevereiro de 1967; revoga a Lei № 11.161, de 5 de agosto de 2005; e institui a Política de Fomento à Implementação de Escolas de Ensino Médio em Tempo Integral. Disponível em: <http://www.planalto.gov.br/ ccivil 03/Ato2015-2018/2017/Lei/L13415.htm>. Acesso em: 22 jan. 2019.

BRASIL. Decreto № 7.566, de 23 de setembro de 1909. Cria nas Capitais dos Estados da República Escolas de Aprendizes Artífices para o ensino profissional primário e gratuito. Disponível em: <https://www2.camara.leg.br/ legin/fed/decret/1900-1909/decreto-7566-23-setembro-1909-525411-norma-pe.html>. Acesso em: em 20 jun.2019.

BRASIL. Decreto № 2.208, de 17 de abril de 1997. Regulamenta o § 2 o do art. 36 e os arts. 39 a 42 da Lei no 9.394, de 20 de dezembro de 1996, que estabelece as diretrizes e bases da educação nacional. Revogado pelo Decreto no 5.154 , de 2004. Disponível em: <http://www.planalto.gov.br/ccivil_03/decreto/D2208.htm>. Acesso em: 20 jun.2019. 
BRASIL. Decreto № 5154, de 23 de julho de 2004. Regulamenta o § 20 do art. 36 e os arts. 39 a 41 da Lei № 9.394, de 20 de dezembro de 1996, que estabelece as diretrizes e bases da educação nacional, e dá outras providências. Disponível em: <http://www.planalto.gov.br/ccivil_03/Ato2004-2006/2004/ Decreto/D5154.htm>. Acesso em: 20 jun. 2019.

BRASIL. Medida Provisória № 746, de 22 de setembro de 2016. Institui a Política de Fomento à Implementação de Escolas de Ensino Médio em Tempo Integral, altera a Lei № 9.394, de 20 de dezembro de 1996, que estabelece as diretrizes e bases da educação nacional, e a Lei № 11.494 de 20 de junho 2007, que regulamenta o Fundo de Manutenção e Desenvolvimento da Educação Básica e de Valorização dos Profissionais da Educação, e dá outras providências. Disponível em: <http://www.planalto.gov.br/ccivil_03/_Ato2015-2018/ 2016/Mpv/mpv746.htm>. Acesso em 23 jan. 2019.

BRASIL. MEC. CNE. CEB. Resolução № 6, de 20 de setembro de 2012. Define Diretrizes Curriculares Nacionais para a Educação Profissional Técnica de Nível Médio (DCNEPTNM). Disponível em: < http://portal.mec.gov.br/index.php? option $=$ com_docman\&view $=$ download\&alias $=11663$-rceb006-12-pdf\&category_slug =setembro-2012-pdf\&ltemid=30192 > . Acesso em: 22 jan. 2019.

BRASIL. MEC. CNE. CEB. Resolução № 3, de 21 de novembro de 2018. Atualiza as Diretrizes Curriculares Nacionais para o Ensino Médio. Disponível em: < $\underline{\text { http: } / /}$ portal.mec.gov.br/docman/novembro-2018-pdf/102481-rceb003-18/file >. Acesso em: 23 jan. 2019.

CIAVATTA, M.; RAMOS, M. Ensino médio e educação profissional no Brasil: dualidade e fragmentação. Revista Retratos da Escola, Brasília, v.5, n.8, p.27-41, jan./jun., 2011.

CUNHA, L. A. O ensino de ofícios artesanais e manufatureiros no Brasil escravocrata. São Paulo: Editora UNESP, Brasília, DF: Flacso, 2000a.

CUNHA, L. A. O ensino de ofícios nos primórdios da industrialização. São Paulo: Editora UNESP, Brasília, DF: Flacso, 2000b.

CUNHA, L. A. O ensino profissional na irradiação do industrialismo. São Paulo: Editora UNESP, Brasília, DF: Flacso, 2000c.

CUNHA, É. V. R. da; LOPES, A. C. Base nacional comum curricular no Brasil: regularidade na dispersão. Investigación Cualitativa, v.2, n.2, p.23-35, 2017.

FRIGOTTO, G.; CIAVATTA, M.; RAMOS, M. (Orgs.). Ensino Médio Integrado: concepções e contradições. 3. ed. São Paulo: Cortez, 2012, p. 107-128.

MANFREDI, S. M. Educação Profissional no Brasil: atores e cenários ao longo da história. Jundiaí: Paco Editorial, 2016.

MOURA, H. D. A relação entre a educação profissional e a educação básica na CONAE 2010: possibilidades e limites para a construção do novo plano nacional de educação. Educação e Sociedade, Campinas, v.31, n.112, p.875-894, jul./set., 2010. 
PACHECO, E. (Org.). Institutos Federais: uma evolução na Educação Profissional e Tecnológica. São Paulo: Moderna, 2011.

PASSOS, A. B. T. A Educação Ambiental e a produção de tecnologias sociais na Educação Profissional e Tecnológica. 2018. 143 f. Dissertação (Programa de PósGraduação em Educação) - Instituto Federal de Educação, Ciência e Tecnologia Sul-riograndense, Pelotas, 2018.

RAMOS, M. N. O currículo para o ensino médio em suas diferentes modalidades: concepções, propostas e problemas. Educação e Sociedade, Campinas, v.32, n.116, p.771-788, jul./set. 2011.

ROBALLO, E. C.; LOTTERMANN, O. A educação profissional no Brasil. In: HAMES, C.; ZANON, L. B.; PANSERA-DE-ARAÚJO, M. C. (Orgs.). Currículo integrado, educação e trabalho: saberes e fazeres em interlocução. ljuí: Ed. Unijuí, 2016. p.37-56.

SANTOS, L. L. Administrando o currículo ou os efeitos da gestão no desenvolvimento curricular. Educação em Revista, Belo Horizonte, v.33, p.1-22, 2017.

SILVA, M. R. da. O Ensino Médio precisa de uma base nacional comum (BNCC)?

Observatório do Ensino Médio da Universidade Federal do Paraná. Disponível em: <http://www.observatoriodoensinomedio.ufpr.br/o-ensino-medio-precisa-de-umabase-nacional-comum-bncc/>. Acesso em: 16 jan. 2019.

SILVA, M. R. da. A BNCC da reforma do ensino médio: o resgate de um empoeirado discurso. Educação em Revista, Belo Horizonte, v.34, p.1-15, 2018.

ZITZKE. V. A. A contribuição da educação ambiental para o ensino médio integrado à educação profissional técnica. 2018. 218 f. Dissertação (Programa de Pós-Graduação em Educação) - Instituto Federal de Educação, Ciência e Tecnologia Sul-rio-grandense, Pelotas, 2018.

ZITZKE, V. A.; CALIXTO, P. M; BIGLIARDI, R. V. A presença da dualidade estrutural no Ensino Médio Integrado à Educação Profissional Técnica: um estudo de caso no IFSUL/CAVG. In: COLÓQUIO NACIONAL, 4., COLÓQUIO INTERNACIONAL A PRODUÇÃO DO CONHECIMENTO EM EDUCAÇÃO PROFISSIONAL: A REFORMA DO ENSINO MÉDIO E SUAS IMPLICAÇÕES PARA A EDUCAÇÃO PROFISSIONAL, 2017, Natal. Anais... Natal/RN: IFRN, v.1, p.1-14, 2017. 